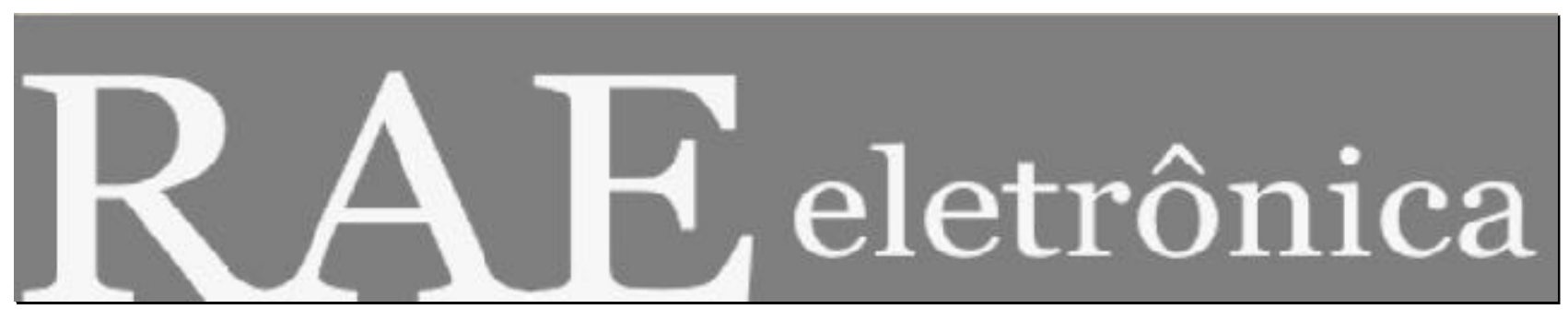

FÓRUM - GESTÃO NO BRASIL: ENFOCANDO PROCESSOS E RELACIONAMENTOS

\title{
APRESENTAÇÃO: EM BUSCA DO QUE TORNA A GESTÃO NO BRASIL PARTICULAR
}

Por:

Eduardo Davel Université du Québec

Sylvia Constant Vergara, FGV-EBAPE

Editores convidados

RAE-eletrônica, v. 4, n. 1, Art. 11, jan./jul. 2005

http://www.rae.com.br/eletronica/index.cfm?FuseAction=Artigo \&ID=3761\&Secao=FOR.GEST.B \&V olume $=4 \&$ Numero $=1 \&$ Ano $=2005$

CCopyright, 2005, RAE-eletrônica. Todos os direitos, inclusive de tradução, são reservados. É permitido citar parte de artigos sem autorização prévia desde que seja identificada a fonte. A reprodução total de artigos é proibida. Os artigos só devem ser usados para uso pessoal e nãocomercial. Em caso de dúvidas, consulte a redação: raeredacao@fgvsp.br.

A RAE-eletrônica é a revista on-line da FGV-EAESP, totalmente aberta e criada com o objetivo de agilizar a veiculação de trabalhos inéditos. Lançada em janeiro de 2002, com perfil acadêmico, é dedicada a professores, pesquisadores e estudantes. Para mais informações consulte o site www.rae.com.br/eletronica.

RAE-eletrônica

ISSN 1676-5648

(C2005 Fundação Getulio Vargas - Escola de Administração de Empresas de São Paulo.

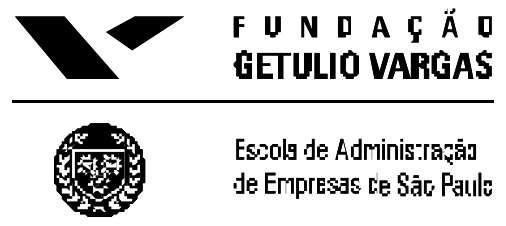




\section{FÓRUM - GESTÃO NO BRASIL: ENFOCANDO PROCESSOS E RELACIONAMENTOS}

\section{APRESENTAÇÃO: EM BUSCA DO QUE TORNA A GESTÃO NO BRASIL PARTICULAR}

O fórum proposto se compõe de três artigos que nos estimulam a estudar as particularidades da gestão no Brasil, assim como refletir sobre elas em uma perspectiva focada em processos e relações humanas. Com base em pesquisa empírica em diversos contextos organizacionais, os autores tratam de aspectos relevantes das representações sociais e da microestratégia, da cultura brasileira, da identidade organizacional, da privatização, do espaço organizacional.

Microestratégia é o processo de desenvolvimento de estratégias que acontece no cotidiano da vida organizacional. Neusa Cavedon e Deise Ferraz avaliam como tal processo é constituído, por representações e significações partilhadas. Por meio de um trabalho etnográfico com observação participante e incluindo história de vida, as autoras exploram o universo de quatro empresas comerciais situadas no Viaduto Otávio Rocha em Porto Alegre: um sebo, uma loja de artigos para presentes, uma loja de artigos religiosos e uma barbearia. $\mathrm{O}$ estudo contribui para elucidar a concepção processual da estratégia calcada nas representações socialmente partilhadas. Destas, duas se revelam determinantes para a orientação estratégica das empresas comerciais estudadas. Uma é a representação negativa desse viaduto como um ambiente violento, com produtos e serviços de baixa qualidade. A outra é a representação da Prefeitura como entidade que cuidará, organizará, e protegerá as empresas do viaduto, resolvendo os diversos problemas administrativos e organizacionais enfrentados no cotidiano. Essas duas representações permitem desvendar a cultura elitista e paternalista que afeta o desenvolvimento de estratégias inexpressivas ou com baixo teor de iniciativa, pois são apoiadas na passividade, na comodidade e na expectativa de que instâncias superiores tomarão as decisões necessárias. $\mathrm{O}$ trabalho de Neusa e Deise sugere uma questão importante: até que ponto as teorias comumente elaboradas pelos pesquisadores em estratégia iluminam realmente a prática cotidiana?

Cultura é o fenômeno abordado no artigo de Hilka P. V. Machado. Mais precisamente, ela explora a relação entre cultura brasileira e identidade organizacional. Admitindo identidade organizacional como um composto representacional, ela infere sobre o modo como os valores e as crenças culturais interferem nesse composto. Ao entrevistar alguns integrantes da organização Sonho Meu - pseudônimo de organização do setor de serviços -, algumas dimensões culturais relevantes para se compreender a identidade organizacional são identificadas. Tais dimensões dizem respeito à informalidade, à proximidade, ao afeto, à expressão emocional e ao paternalismo que impregnam as relações sociais e interpessoais dos funcionários. $\mathrm{O}$ estudo reforça, então, ensaios teóricos sobre os traços da cultura brasileira que explicam práticas administrativas e organizacionais. Enfatiza a importância de se estudar a relação entre identidade e cultura em seu sentido mais amplo, perpassando múltiplos níveis, como a família, a sociedade e uma região. $\mathrm{O}$ estudo provoca nossa reflexão, por exemplo, para descobrir se a busca de proximidade, de afeto e de expressão emocional nas relações sociais que se desenvolvem nas organizações é fator de coesão, dedicação e comprometimento, ou se é fator de dependência, passividade e baixa capacidade crítica. 
FÓRUM - GESTÃO NO BRASIL: ENFOCANDO PROCESSOS E RELACIONAMENTOS

APRESENTAÇÃO: EM BUSCA DO QUE TORNA A GESTÃO NO BRASIL PARTICULAR Eduardo Davel - Sylvia Constant Vergara

Também contemplando aspectos da identidade organizacional, Alexandre Carrieri e Denise Pereira exploram em seu artigo a noção de "territorialização" como processo cíclico de desocupação e reocupação do espaço organizacional no contexto da privatização da Telemig/Telemar-Minas nos anos 1990. Eles contribuem para aprofundar a concepção de espaço organizacional de duas formas. A primeira consiste em concebê-lo como algo que vai além do aspecto físico para incluir a percepção subjetiva da posição e do papel que nele se ocupa. Ou seja, ocupar um espaço diz respeito aos aspectos sociais, políticos, identitários e afetivos que sustentam tal ocupação. A segunda forma se refere a uma concepção dinâmica do espaço organizacional como um movimento constante de desocupação e reocupação, de desapropriação e reapropriação. Todavia, a reocupação e reapropriação do novo espaço organizacional na Telemig/Telemar-Minas não se apóia em vínculos da mesma natureza que os do passado. Os vínculos sociais e interpessoais se refazem de maneira mais efêmera, pois as pessoas não têm a mesma vivência organizacional, não se conhecem tanto, não se dedicam tanto, não se enraízam tanto no novo espaço de trabalho. Ao contrastarmos essa experiência com a observação de Hilka Machado de que a busca de proximidade, afeto e expressão emocional nas relações interpessoais no trabalho é algo significativo da cultura brasileira, não encontraríamos aí uma contradição frutífera para alimentar nossa reflexão e nossas pesquisas?

Um ponto emergente dos três artigos é, sem dúvida, a natureza dos vínculos criados entre pessoas. Na experiência retratada por Alexandre e Denise, o enfraquecimento desses vínculos é fator de preocupação e desconforto. Na experiência estudada por Hilka, os vínculos buscam proximidade, afeto e expressão emocional. Na experiência observada por Neusa e Deise, os vínculos refletem a busca coletiva de um sentimento de proteção paterna. Nos três casos, debatemo-nos com a textura das relações humanas e com a questão fundamental do grau de dependência ou independência afetiva que se desenvolve. No caso da Telemig/Telemar-Minas, a independência afetiva que aparece na reocupação do espaço é criticada, enquanto na Sonho Meu é a proximidade afetiva, vista como fator de passividade. A imagem paternal também é criticada por Neusa e Denise como sendo fator de passividade e comodidade.

Muitos dirão que a textura das relações interpessoais no contexto brasileiro são baseadas na dependência e, no entanto, deveriam sê-lo predominantemente na independência. Outros, no entanto, dirão que deveriam ser baseadas na interdependência. Certamente, o foco nas relações com base na interdependência enriquece nossa compreensão do universo organizacional e interpessoal, pois nos permite desenvolver uma concepção menos fatalista e mais dinâmica daquele universo. Dessa forma, uma questão que emerge do fórum é: como estudar a gestão e organização no Brasil, explorando a natureza interdependente das relações humanas em suas dimensões afetivas, emocionais, políticas e sociais? De que forma o foco na interdependência aprimora nosso entendimento de organizações e sua gestão, sobretudo organizações e gestão no Brasil? Quais teorias nos ajudariam a seguir esse caminho? Qual procedimento metodológico privilegiar?

Ao menos três grandes desafios devem ser enfrentados no estudo das relações e de seu caráter interdependente: (1) espistemológico e conceitual; (2) prático e gerencial; e (3) contribuitivo e reflexivo (Davel e Vergara, 2005). O desafio epistemológico e conceitual envolve uma concepção da organização como processo constante e inacabado . Tal visão pode ser situada, por exemplo, no livro de Karl Weick (1979) que estimula a mudança do foco de análise da organização como entidade relativamente estável, acabada, com fronteiras bem definidas, para uma compreensão da organização como resultante de processos de organização (organizing) contínuos, cambiantes, produzidos pelo relacionamento humano. Concebe-se, então, a organização como uma entidade que se constrói, a cada instante, de ações, comunicações, arranjos e redes de relações. 


\section{FÓRUM - GESTÃO NO BRASIL: ENFOCANDO PROCESSOS E RELACIONAMENTOS \\ APRESENTAÇÃO: EM BUSCA DO QUE TORNA A GESTÃO NO BRASIL PARTICULAR Eduardo Davel - Sylvia Constant Vergara}

Uma abordagem que nos permita estudar as organizações do ponto de vista relacional pode ter por base múltiplas teorias sociais, tais como a psicologia social, o interacionismo, o construtivismo e a teoria da estruturação (Baxter e Montgomery, 1996; Emirbayer, 1997; Gergen, 1994). Além disso, abordagens centradas na dimensão relacional para estudar as organizações estão disponíveis (Alter, 2000; Cameron, Dutton et al., 2003; Dutton, 2003; Hosking e Morley, 1991; Hosking, Dachler e Gergen, 1995; Kahn, 1998; Watson, 1999, 2002, 2005). Devemos, no entanto, esclarecer que quando se fala de enfoque relacional para estudar organizações e gestão no Brasil, não se argumenta que uma sociedade ou uma organização seja mais relacional do que outra, já que as relações representam a base da existência humana e são imprescind́veis a qualquer comunidade ou grupo. Todavia, podemos apreender a textura das relações a partir de padrões decorrentes do desenvolvimento socio -histórico de uma determinada sociedade (Davel e Vergara, 2005).

A proposta deste fórum foi instigar a produção de estudos sobre aquilo que pode nos conduzir a apreender as particularidades dos processos de organização em contexto brasileiro. Analisando o fórum numa perspectiva relacional, ele vale pelo potencial que apresenta em estimular a reflexão e novas pesquisas sobre a temática. Vale como processo e não como verdade acabada. Nesse sentido, o fórum não pretende dar uma resposta fechada à questão de explicar as particularidades dos processos de organização no Brasil. Ele se inscreve em um processo contínuo para podermos produzir pesquisas que tenham o potencial de explicar de que maneira os tipos de interação humana no Brasil podem contribuir para reformularmos e repensarmos as teorias organizacionais. Dessa forma, o fórum se inscreve no esforço de encontrarmos caminhos originais, pertinentes e com rigor acadêmico para desenvolver pesquisa sobre gestão e organizações.

\section{REFERÊNCIAS BIBLIOGRÁFICAS}

ALTER, N. L’innovation ordinaire. Paris: Presses Universitaires de France, 2000.

BAXTER, L. A.; MONTGOMERY, B. M. Relating: Dialogues and Dialectics. New York: The Guilford Press, 1996.

BERSCHEID, E. The greening of relationship science. American Psychologist, v. 54, n. 4, p. 260-266, 1999.

BRADBURY, H.; LICHTENSTEIN, B. M. Relationality in organizational research: exploring the space between. Organization Science, v. 11, n. 5, p. 551-564, 2000.

CAMERON, K. S.; DUTTON, J. E.; QUINN, R. E. Positive organizational scholarship: foundations of a new discipline. San Francisco: Berrett-Koehler Publishers, 2003.

DAVEL, E.; VERGARA, S. Desafios relacionais nas práticas de gestão e de organização. Revista de Administração de Empresas, v. 45, n. 1, p. 10-13, 2005.

DUTTON, J. E. Energize Your Workplace: How to Create and Sustain High-Quality Connections at Work. San Francisco: Jossey-Bass, 2003. 


\section{FÓRUM - GESTÃO NO BRASIL: ENFOCANDO PROCESSOS E RELACIONAMENTOS \\ APRESENTAÇÃO: EM BUSCA DO QUE TORNA A GESTÃO NO BRASIL PARTICULAR Eduardo Davel - Sylvia Constant Vergara}

EMIRBAYER, M. Manifesto for a relational sociology. American Journal of Sociology, v. 103, n. 2, p. 281-317, 1997.

GERGEN, K. J. Realities and Relationships: Souding in Social Construction. Cambridge: Harvard University Press, 1994.

HOSKING, D.; MORLEY, I. E. A social psychology of organizing: people, processes and contexts. Hertfordshire: Harvester Wheatsheaf, 1991.

HOSKING, D.-M.; DACHLER, H. P. e GERGEN, K. J. Management and Organization: Relational Alternatives to Individualism. Aldershot: Avebury, 1995.

KAHN, W. A. Relational systems at work. Research in Organizational Behavior, v. 20, p. 39-76, 1998.

WATSON, T. J.; HARRIS, P. The Emergent Manager. London: Sage Publications, 1999.

WATSON, T. J. Organising and Managing Work: Organisational, Managerial and Strategic Behaviour in Theory and Practice. London: Pearson Education, 2002.

WATSON, T. J. Organização e trabalho em transição: da lógica "sistêmico-controladora à lógica "processual-relacional”. Revista de Administração de Empresas, v. 45, n. 1, p. 10-13, 2005.

WEICK, K. E. The Social Psychology of Organizing. Menlo Park: Addison-Wesley Publishing, 1979.

\section{Eduardo Davel}

Professor da Télé-université, Université du Québec, Canadá

E-mail: edavel@teluq.uquebec.ca

\section{Sylvia Constant Vergara}

Professora da FGV-EBAPE

E-mail: vergara@fgv.br 